\title{
Sp3 Expression in Immune Cells: A Quantitative Study
}

\author{
Maria C. Grekova, Kilian Salerno, Radha Mikkilineni, and John R. Richert \\ Departments of Microbiology and Immunology (MCG, KS, RM, JRR), and Neurology (JRR), Georgetown University \\ Medical Center, \\ Washington $D C$
}

\begin{abstract}
SUMMARY: We previously reported the lack of expression of the bifunctional transcription factor Sp3 in peripheral blood mononuclear cells from most patients with multiple sclerosis (MS) (Grekova et al, 1996). An RT-PCR technique was developed to evaluate Sp3 mRNA levels in peripheral blood mononuclear cell subsets. Semi-quantitative and quantitative competitive RT-PCR assays were used to compare the level of Sp3 expression among subjects and among immune cell subsets. The competitor DNA fragment contained a deletion from the normal Sp3 cDNA sequence. The wild-type Sp3 cDNA and the competitor DNA fragment amplified with equal efficiency, and the two PCR products were distinguished by size. These studies demonstrated that normal $\mathrm{CD}^{+}$and $\mathrm{CD}^{+} \mathrm{T}$ cells, B cells, and macrophages expressed comparable amounts of Sp3 mRNA. No Sp3 expression could be detected in normal natural killer cells nor in any of these cell types from Sp3-negative MS patients. We propose that transcription of the Sp3 gene is blocked in immune cells from most patients with MS and that this contributes to the development of central nervous system inflammation in the disease. (Lab Invest 2002, 82:1131-1138).
\end{abstract}

$T_{\text {ber of the } \mathrm{Sp} 1 \text { family that binds } \mathrm{GC} / \mathrm{T} \text { box }}$ elements (Hagen et al, 1992; Kingsley and Winoto 1992; Suske, 1999), may activate or suppress the expression of several genes with known function within the immune system, including Fas (Pang et al, 1998), IL-10 (Tone et al, 2000), transforming growth factor $\beta$ (Udvadia et al, 1995), and several T cell receptor (TCR) $\alpha$-chain variable region gene segments (Kingsley and Winoto, 1992). Although Sp3 is ubiquitously expressed in normal human tissue (Hagen et al, 1992), we have previously reported that Sp3 transcripts cannot be detected in unfractionated peripheral blood mononuclear cells (PBMCs) from most patients with multiple sclerosis (MS) (Grekova et al, 1996), a putative autoimmune disease of the central nervous system. This finding was relatively diseasespecific, because seven of eight patients with rheumatoid arthritis or systemic lupus erythematosus normally expressed this gene. Sp3 gene organization seems to be normal in patients with MS (Grekova et al, 2000) and excessively rapid degradation of Sp3 mRNA was ruled out as a potential explanation for this phenomenon (manuscript in preparation). Thus, it seems that deficient transcription of the Sp3 gene most likely accounts for this finding.

\section{DOI: 10.1097/01.LAB.0000029149.38881.84}

Received January 29, 2002.

Supported by NIH RO1NS37341, National Multiple Sclerosis grant RG2745-C-11, and the Straus, Bou, Wadsworth, and Rybicki Funds.

Address reprint requests to: Dr. John R. Richert, Department of Microbiology and Immunology, Room NE303, Med Dent Building, Georgetown University Medical Center, 3900 Reservoir Rd., NW, Washington, DC 20007.E-mail: richertj@georgetown.edu
Our initial screening involved the use of differential display to identify genes that were differentially expressed in identical twins who are discordant for MS. These studies, and our subsequent more extensive population studies, used unfractionated PBMCs, because it is not certain which subset(s) of leukocytes are most importantly involved in MS pathogenesis. The current study examines the expression of Sp3 in PBMC subsets from patients with MS and from healthy controls. To adequately quantitate $S p 3$ gene expression in these cells, we developed and applied a quantitative competitive (qc) RT-PCR assay for detecting Sp3 transcripts.

\section{Results}

\section{$\beta$-actin and Sp3 RT-PCR with PBMC Subsets}

The housekeeping gene $\beta$-actin was used in our RT-PCR experiments for cDNA quality control. The set of human $\beta$-actin primers amplified a 661 -bp PCR product, and only cDNAs that were strongly positive for $\beta$-actin were used in these studies.

\section{Generation and Testing of the Standard}

Generation and testing of suitable internal standards and the choice of primer pairs are among the most crucial and time-consuming aspects of establishing a competitive PCR protocol. Internal standards for competitive PCR or RT-PCR are DNA or RNA fragments sharing the primer recognition sequences. The easiest way to distinguish between wild-type template and internal standard is by differences in the size of the two products (Zimmermann and Mannhalter, 1996). The two PCR products (the wild-type and the competitor fragments) were easily distinguishable on a $1.5 \%$ agarose gel (Fig. 1A). The titration assay showed that 
A

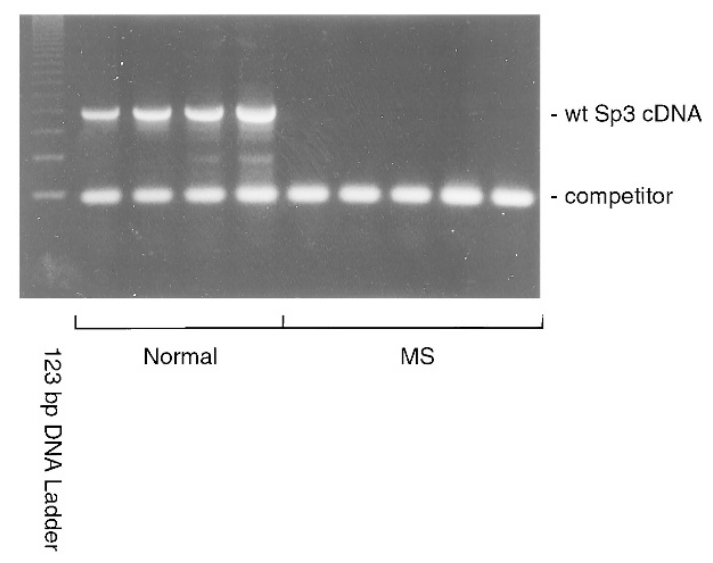

B

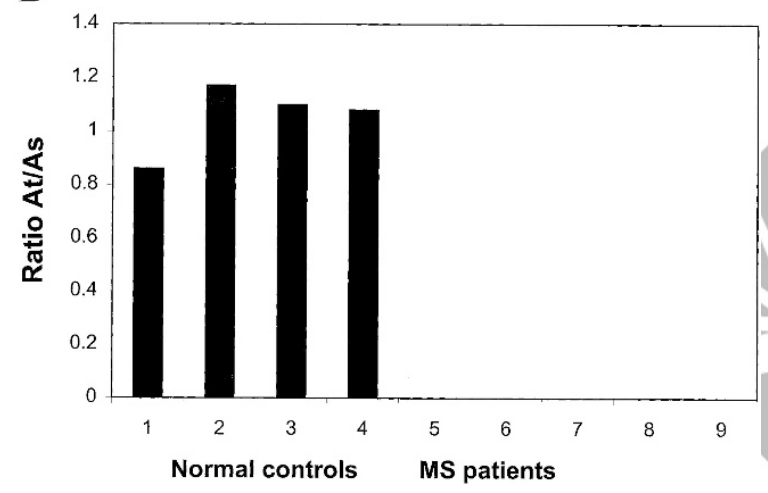

Figure 1.

A, Semiquantitative RT-PCR (sq RT-PCR). A competitor template was introduced to improve the quantitative ability of RT-PCR. The competitor template was identical to the target sequence, except that it contained a deletion that allowed the amplification products to be distinguished by size differences. A titration assay was previously carried out and $12 \mathrm{pg}$ was determined to be the optimal quantity of standard cDNA (competitor) for coamplification. A constant amount of competitor (12 pg) was spiked into PCR reactions containing the experimental cDNA samples from four healthy controls and five patients with multiple sclerosis $(M S)$. The two PCR products (the wild-type [wt] and the competitor fragments) were easily distinguished on a 1.5\% agarose gel. The Sp3 transcripts were detected in peripheral blood mononuclear cells (PBMCs) from all investigated normal controls, but not in PBMCs from patients with MS. $\mathrm{B}$, The band intensities of the PCR products were determined and the ratio of amplified target $(A t)$ to amplified standard $(A s)$ was calculated for four healthy controls and five patients with MS.

the target cDNA, corresponding to $100 \mathrm{ng}$ of reverse transcribed total RNA, could be coamplified successfully with $12 \mathrm{pg}$ of the competitor DNA (see "Materials and Methods"). This amount of the competitor was used in our subsequent semiquantitative experiments.

\section{Sp3 Expression in PBMCs from Patients with MS and Normal Controls}

Sp3 expression in PBMCs from four normal controls and five patients with MS was evaluated using sq RT-PCR with sense and antisense primers designed from the published Sp3 cDNA sequence (Hagen et al, 1992; Kingsley and Winoto, 1992) and $12 \mathrm{pg}$ of the competitor. The Sp3 transcripts were detected in PBMCs from all investigated normal controls. As shown in Figure 1, A and B, the relative level of expression has a tendency to vary to a modest degree among the individuals in the control group. We were unable to amplify Sp3 fragments from unfractionated PBMCs from the patients with MS. These results corroborate our previous findings using standard RTPCR in larger groups of patients and controls (Grekova et al, 1996).

\section{Sp3 Expression in PBMC Subsets}

PBMCs were stained using monoclonal antibodies (mAbs) to cell-specific surface markers and sorted into subsets by flow cytometry. After RNA isolation and reverse transcription with the universal primer oligo $\mathrm{p}(\mathrm{dT}) 15, \mathrm{cDNA}$ quality was tested by PCR with $\beta$-actin primers. Sq RT-PCR was performed with a known quantity of competitor (12 pg) added to the PCR containing the experimental CDNA from the PBMC subpopulations. Both the amplified standard and product derived from the cDNA of interest were distinguished by size. A comparison of the band intensities of the PCR products determined the quantity of the target Sp3 gene product. The ratio of amplified target to amplified standard was then determined. Differences in the ratio gave the relative differences in Sp3 mRNA levels among the PBMC subsets. Results are shown in Figure 2. Although there was variation among the subsets from a given subject (Fig. 2A), $\mathrm{CD}^{+}$and $\mathrm{CD}^{+}{ }^{+} \mathrm{T}$ cells, B cells, and macrophages/ monocytes exhibited roughly comparable levels of Sp3 gene expression when averaged among subjects (Fig. 2B). No Sp3 transcript could be detected in normal natural killer (NK) cells (Fig. 2), nor in any PBMC subset from patients with MS (Fig. 3).

These results were confirmed by qc RT-PCR. A typical example of a qc RT-PCR gel is shown in Figure 4. The highest level of Sp3 gene expression using this technique (Fig. 5) was found in normal T-lymphocytes. $\mathrm{CD}^{+}{ }^{+} \mathrm{T}$ cells in particular exhibited a modestly higher level of expression relative to the other subpopulations.

\section{Discussion}

MS is presumed to be an autoimmune disease of the central nervous system. Over the years, T cells, B cells, macrophages (or microglia within the central nervous system), and NK cells have all been suggested to be of etiologic importance in the disease. For this reason, our initial studies of differential gene expression in general, and $\mathrm{Sp} 3$ in particular, used unfractionated PBMCs so that we would not inadvertently overlook an important cell type or gene expression system in this work.

Once we had identified Sp3 as a gene that is deficiently expressed in immune cells from patients with MS, it became important to determine the PBMC subsets involved. Our early findings of deficient expression could have, for example, involved a single large subset such as $\mathrm{CD}^{+}$or $\mathrm{CD} 4^{+} \mathrm{T}$ cells. In such a case, the loss of expression in just one of these subsets could have led to data that gave the impres- 
A

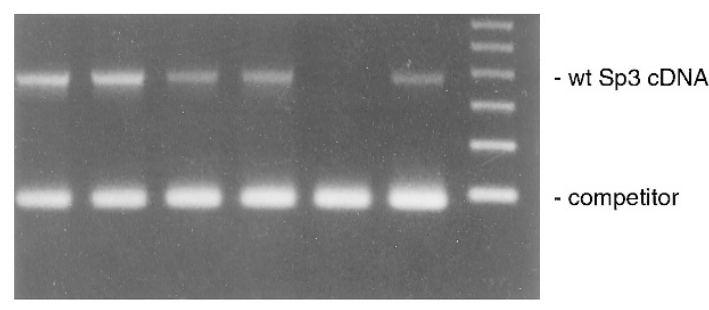

B

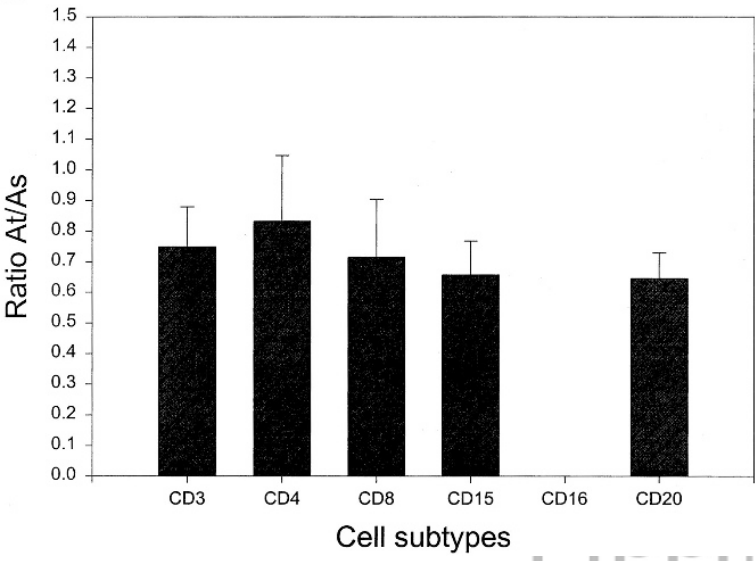

Figure 2.

A, Detection of $\mathrm{Sp} 3$ expression in different PBMC subpopulations from a normal individual by sq RT-PCR. Lane 1, CD $3^{+}$T cells; Lane 2, CD4 $4^{+}$T cells; Lane $3, \mathrm{CD}^{+} \mathrm{T}$ cells; Lane $4, \mathrm{CD}^{+} 5^{+}$monocytes/macrophages; Lane 5 , $\mathrm{CD}_{16}{ }^{+} \mathrm{NK}$ cells; Lane $6, \mathrm{CD} 20^{+}$B cells. B, Mean level of expression of the Sp3 gene in PBMC subtypes from healthy controls, \pm standard error, estimated by sq RT-PCR. A comparison of the band intensities of the PCR products and the ratios of amplified target $(A t)$ to amplified standard $(A s)$ were determined.

sion of an across-the-board loss of expression, particularly if the RT-PCR procedure had been too insensitive to detect persistent expression in minor PBMC subsets. Alternatively, the loss of expression could have involved multiple subsets.

We used qc RT-PCR to evaluate abundant cell populations and initially adapted this to sq RT-PCR for evaluation of small subpopulations. The latter included populations from which we had difficulty generating enough cDNA to perform classic quantitative PCR that requires multiple assay tubes, each containing CDNA that has been reverse transcribed from cellular RNA. Like classic quantitative PCR, sq RT-PCR uses a competitor oligonucleotide and primers that initiate amplification of cDNAs of both wild-type and synthetic oligonucleotide origin, leading to amplification of bands of different sizes for these two types of CDNA, respectively. Our results show that this applied technique is sensitive, accurate, and reproducible. We were eventually able to successfully perform qc RT-
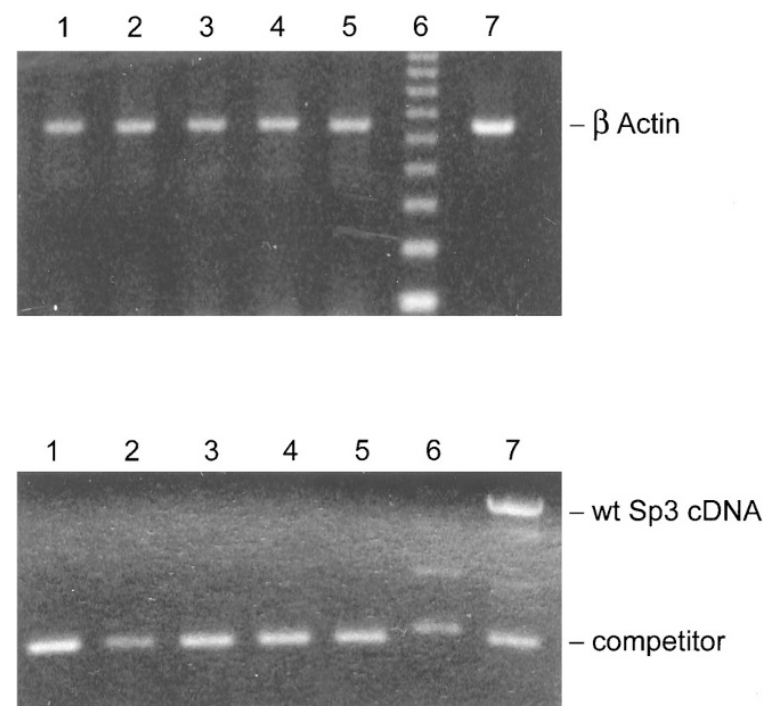

Figure 3.

Top, The housekeeping gene $\beta$-actin was used in all RT-PCR experiments as an internal control for cDNA quality. Bottom, Lack of expression of the Sp3 gene in PBMC subpopulations from a representative MS patient. Lanes for both gels: Lane $1, \mathrm{CD}^{+} \mathrm{T}$ cells; Lane 2, CD8 ${ }^{+} \mathrm{T}$ cells; Lane $3, \mathrm{CD} 15^{+}$ monocytes/macrophages; Lane 4, CD16 ${ }^{+}$NK cells; Lane $5, \mathrm{CD}_{2} 0^{+}$B cells; Lane 6, 123 bp DNA Ladder; Lane 7, positive control.
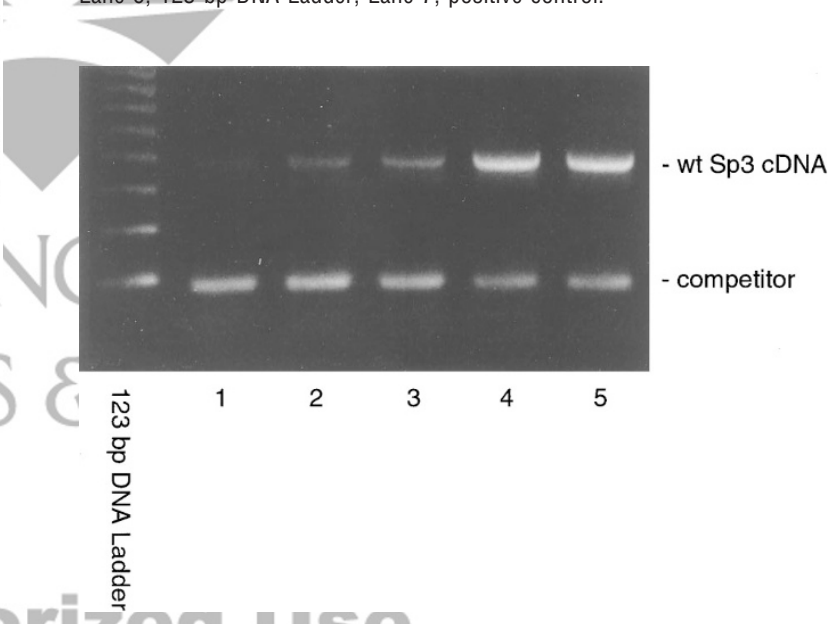

\section{Figure 4.}

Representative example of quantitative competitive (qc) RT-PCR analysis for Sp3 expression in normal CD8 ${ }^{+}$cells. A constant amount of target CDNA was coamplified with five different amounts of the competitor in serial dilutions (lanes 1 to 5): 1:2, 1:4, 1:8, 1:16, 1:32, with the highest quantity being $50 \mathrm{pg}$. By extrapolating the data to the point at which the amplification of the CDNA and the competitive fragment were identical, the concentration of $\mathrm{Sp} 3$ in $\mathrm{CD}^{+}$ cells was determined to be $1.13 \mathrm{pg} / \mathrm{mg}$ of total RNA.

PCR on nearly all samples (Fig. 5), and these data were used to corroborate our initial findings.

The quantitative measurement of gene expression requires consistent and reliable standards. Two categories of standards, endogenous and exogenous, are currently used for quantitative PCR. The expression of a housekeeping gene (eg, $\beta$-actin, GAPDH, ribosomal RNA) is commonly used as an endogenous control to measure the target gene expression, but some authors (eg, Busin, 2000; Foss et al, 1998) have reported that the expression of these housekeeping genes is also variable among cell lines, tissues, and cell cycle 


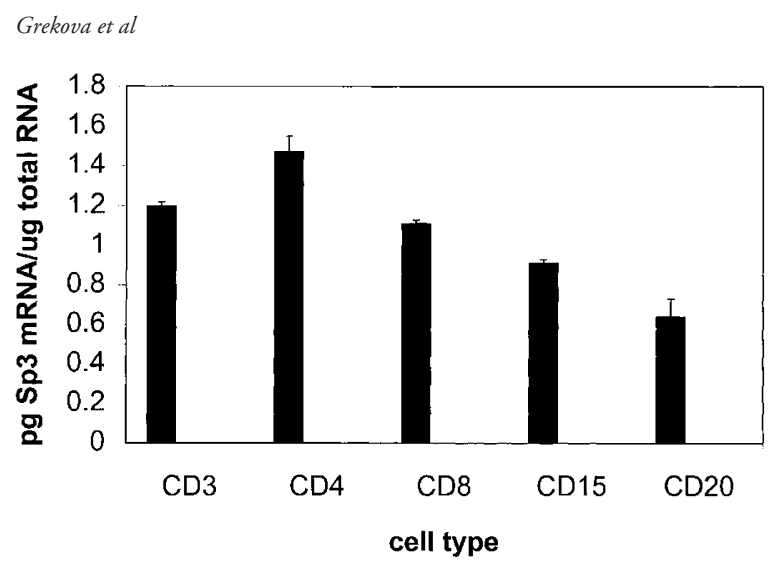

Figure 5.

Quantitative analysis of Sp3 mRNA levels in normal immune cells from four donors by qc RT-PCR. The bands were quantitated by densitometry and the ratios of target $(A t)$ to competitor $(A s)$ were plotted in each case against the amount of competitor added. The amounts of target and competitor were assumed to be equal when the ratio was $1: 1, \log _{10}=0$. The absolute amount of target was determined as picograms of Sp3 RNA per microgram of total cellular RNA.

steps. Although $\beta$-actin does not serve as an adequate endogenous control to measure $S p 3$ gene expression in PBMCs, it was used in our studies as a quality control for RNA isolation and cDNA preparation. Exogenous standard-based quantitative PCR has previously been shown to be an accurate and reliable method for the quantitation of gene expression (Ke et al, 2000; Riedy et al, 1995). In the current study, we used a DNA competitor consisting of an exogenous standard with a deletion from the wild-type Sp3 fragment. Some authors have proposed the addition of RNA competitors during the RT step to standardize the reverse transcription. However, Auboeuf and Vidal (1997) have shown identical patterns of expression of different genes using RNA and DNA competitors in the same experiments, indicating that the use of RNA competitors is not necessary.

In the construction of the competitor template, exact quantitation represents a critical point for the success of this technique. The competitor, to act as a functionally appropriate internal standard, must behave as much as possible like the template during the assay. For this reason, the competitor must have comparable dimensions and the same primer recognition sites as the target. The simplest approach for obtaining a synthetic competitor is the introduction of a deletion or insertion in the center of the competitor. A standard (competitor) with a deletion in the middle of the wild-type Sp3 fragment was used in this study. It was produced using a modification of the overlap extension technique (Raftery et al, 1993). Two primers containing complementary sequences to each other were annealed and amplified with the external Sp3 primers in the same tube. The competitor, prepared according to the described method, can be used directly as linear sequences. Under the conditions of qc RT-PCR, the amount of competitor added to the reaction is equal to the amount of target when the molar ratio of the products is one $\left(\log _{10}=0\right)$. Our studies demonstrate that qc RT-PCR, and then by evaluation of the PCR products in ethidium bromidestained agarose gels, is a reliable and accurate method to quantify Sp3-specific mRNA.

The results reported here demonstrate that the $S p 3$ gene is transcribed in normal $\mathrm{CD}^{+}, \mathrm{CD}^{+}$, and $\mathrm{CD}^{+}$ $\mathrm{T}$ cells, in $\mathrm{B}$ cells, and in macrophages, but not to a detectable level in normal NK cells. All cellular subsets from patients affected with MS exhibited the loss of Sp3 gene expression.

One potential explanation for our original results in unfractionated MS PBMCs is that an agent of environmental origin binds to one or more of the regulatory elements of the Sp3 gene and blocks its expression. In such a case, one might postulate that MS results from a chronic infection of immune cells that leads to diminished expression of Sp3 and to the subsequent alteration in expression of genes on which Sp3 normally acts. This could, for example, potentially lead to decreased expression of the anti-inflammatory cytokine TGF $\beta$ and increased expression of both the proinflammatory cytokine TNF $\alpha$ and certain TCR alpha chain variable region gene segments. However, if this environmental agent were viral, one might have expected a more restricted pattern of tropism, for example, affecting only one PBMC subset. Nevertheless, an infectious agent with a more widespread tropism cannot be ruled out at this time. The data are perhaps more consistent with an indirect effect of an environmental agent on Sp3 expression, for example, via a cytokine that acts on multiple PBMC subsets. We suspect that an environmental agent is directly or indirectly responsible for suppressing $S p 3$ gene expression in MS for the following reasons: 1) the original screening of MS and non-MS PBMCs that identified $\mathrm{Sp} 3$ as a potential gene of importance involved identical twins, such that any difference in gene expression had to be due to an acquired rather than genetic cause; and 2) our studies of genomic DNA to date have failed to detect any differences in Sp3 gene sequence or organization among patients with $\mathrm{MS}$ and controls (Grekova et al, 2000). Those studies included sequencing of the known coding regions and Southern blot analyses. The latter would detect major deletions but would likely miss a point mutation unless it occurred at an enzyme restriction site. We are just now obtaining sequence data for the $5^{\prime}$ aspect of the coding region and the $5^{\prime}$ flanking region, so we should be able to answer this question more clearly in the near future. Genome-wide scans in MS have not detected any association between disease and the region of chromosome 7 (7p14-p15.2) to which we localized the Sp3 gene (Grekova et al, 2000).

Our future studies will be aimed primarily at studying the normal and diseased regulation of Sp3 gene expression, with particular emphasis on identifying a factor in MS immune cells that is not found in non-MS cells and that binds to one or more of the regulatory elements of the Sp3 gene and blocks its function. 


\section{Materials and Methods}

\section{PBMC Separation}

PBMCs from four normal controls and five patients with MS were isolated by standard discontinuous Ficoll-Hypaque gradient fractionation. Freshly isolated PBMCs, with $97 \%$ to $99 \%$ cell viability measured by trypan blue exclusion, were used in all experiments. Subsets of immune cells were separated by flow cytometry using mAbs against cell surface antigens. After gradient centrifugation, cells were washed twice with medium RPMI supplemented with $0.5 \%$ human serum albumin (HSA). PBMCs were incubated for 30 minutes at $4^{\circ} \mathrm{C}$ in the dark with $\mathrm{PE}$-conjugated antihuman CD3 (for T lymphocytes), FITC-conjugated anti-human CD15 (for monocytes), FITC-conjugated anti-human CD20 (for B lymphocytes), or FITCconjugated anti-human CD16 (for NK cells). The mAbs were used according to the commercially available protocols (Becton Dickinson, San Diego, California). After washing with PBS ( $\mathrm{pH} 7.4$ ), stained cells were resuspended in medium with $2 \% \mathrm{FCS}$ and were run on a FACStarplus (Becton Dickinson) for analysis and sorting. Each cell subpopulation (99.9\% pure) was washed with cold PBS and used immediately for RNA isolation or the cell pellets were frozen and stored at $-70^{\circ} \mathrm{C}$ until used.

\section{Total RNA Isolation}

Total RNA from each cell subset was isolated using TRI-REAGENT (Molecular Research Center, Cincinnati, Ohio) according to the manufacturer's recommendations. At least $2 \times 10^{6}$ cells were used for each RNA isolation.

\section{cDNA Synthesis}

Frequently, RNA preparations contain small amounts of genomic DNA that may be amplified along with the target cDNA. To eliminate genomic DNA contamination, all RNA samples were treated with DNase I, Amplification Grade (Life Technologies, Rockville, Maryland) before reverse transcription. Two micrograms of total RNA were incubated with 1 unit DNase I at room temperature for 15 minutes. To inactivate the DNase I, 1 ul of 25 mм EDTA was added and samples were heated for 15 minutes at $65^{\circ} \mathrm{C}$. After DNase I treatment, RNA was used directly for reverse transcription.

First-strand cDNA synthesis was performed with SuperScript II Reverse Transcriptase (Life Technologies) in 20 ul volume. The reaction mixtures contained 50 mм Tris-HCL (pH 8.3); 75 mм KCL; 3 mм MgCl $; 10$ mM DTT; 500 mm each of dATP, dCTP, dGTP, and dTTP; and 320 pм Primer p(DT) ${ }_{15}$ (Roche Diagnostics, Indianapolis, Indiana). After incubation at $42^{\circ} \mathrm{C}$ for 2 minutes, 50 units of SuperScript II RT and 10 units of RNase inhibitor were added and the mix was incubated for another 50 minutes at $42^{\circ} \mathrm{C}$. The reaction was terminated at $70^{\circ} \mathrm{C}$ for 15 minutes. Acceptable
cDNA preparations were characterized by strong $\beta$-actin gene expression.

\section{$\beta$-Actin PCR}

PCR was carried out in 20 ul total volume containing 1 $\mu \mathrm{l}$ CDNA, $1 \mu \mathrm{M}$ primers specific for the $\beta$-actin gene (Stratagene, La Jolla, California), 10\% dimethylsulfoxide (DMSO), $200 \mu \mathrm{m}$ of each dNTP, $60 \mathrm{~mm}$ Tris-SO (pH 9.1), $18 \mathrm{~mm}\left(\mathrm{NH}_{4}\right)_{2} \mathrm{SO}_{4}$, with $2 \mathrm{~mm} \mathrm{MgSO}_{4}$. Elongase Enzyme Mix (0.25 U; Life Technologies) was added. The $\beta$-actin fragment was amplified by initial denaturation at $94^{\circ} \mathrm{C}$ for 5 minutes, followed by 35 cycles consisting of $94^{\circ} \mathrm{C}$ for 45 seconds, annealing at $60^{\circ} \mathrm{C}$ for 45 seconds, and extension at $68^{\circ} \mathrm{C}$ for 1.5 minutes in a thermal cycler (Perkin-Elmer, Norwalk, Connecticut), followed by a final extension for 10 minutes at $68^{\circ} \mathrm{C}$. PCR products were resolved on $1.5 \%$ agarose gels stained with ethidium bromide.

\section{Sp3 Oligonucleotide Primers}

A primer pair, referred to as internal primer forward (IPF)-17 plus internal primer reverse (IPR)-18, was designed based on the published Sp3 cDNA sequence (1, 2): 5' GTG CAG TGT CCA GTG GTT CAA 3' (IPF)-17 and 5' GAG AAA CCC GCT CAC CAG T 3' (IPR)-18. These primers are shown as bold sequences in Figure 6.

\section{Standard Sp3 PCR}

PCRs were performed in a 20 -ul volume containing $100 \mathrm{ng}$ reverse transcribed total RNA, $125 \mathrm{pmol}$ of each sense and antisense primer, $10 \mathrm{~mm}$ dNTPs, 60 mm Tris- $\mathrm{SO}_{4}\left(\mathrm{pH}\right.$ 9.1), $1.8 \mathrm{~mm}\left(\mathrm{NH}_{4}\right)_{2} \mathrm{SO}_{4}, 1.5 \mathrm{~mm}$ $\mathrm{MgSO}_{4}$, and $10 \%$ DMSO. Elongase Enzyme Mix (0.5 $\mathrm{U}$; Life Technologies) was added. The Sp3 fragment was amplified by initial denaturation at $94^{\circ} \mathrm{C}$ for 1 minute, and then by 30 cycles consisting of $94^{\circ} \mathrm{C}$ for 30 seconds, annealing at $58^{\circ} \mathrm{C}$ for 30 seconds, and extension at $68^{\circ} \mathrm{C}$ for 30 seconds in a thermal cycler (Perkin-Elmer), followed by a final extension for 1 minute at $68^{\circ} \mathrm{C}$. PCR products were resolved on $1.5 \%$ agarose gels stained with ethidium bromide.

\section{Generation of an Internal cDNA Standard for Competitive Sp3 RT-PCR}

Figure 6 schematically summarizes the three-step construction of the internal standard. The DNA competitor, a 126-bp fragment, was constructed to contain the same primer template sequences as the target, a 464-bp fragment of wild-type Sp3 cDNA. The competitor was designed from the wild-type Sp3 cDNA by deletion of an internal sequence, analogous to the method of Raftery et al (1993). This competitor was synthesized using 66 and 60 nucleotide sense and antisense primers, respectively. The sense primer $\left(\mathrm{SP}_{3} \mathrm{~S}_{2} \text { ) and antisense primer (SP3AS }\right)_{2}$ ) were designed based on the published Sp3 cDNA sequence (Hagen et al, 1992; Kingsley and Winoto, 1992). These primers share an 18 nucleotide complementary region at their 
1) Primer design:

$\mathrm{SP}_{3} \mathrm{~S}_{2}$ (sense primer from nt 237 to $\mathrm{nt} 300$ ):

\title{
5'GTG CAG TGT CCA GTG GTT CAA TAT CAA GTG ATA CCA CAG ATC CAG GTC
}

\author{
AGC AGA TGG TCA GCA GGT 3'
}

$\mathrm{SP}_{3} \mathrm{AS}_{2}$ (antisense primer from $659 \mathrm{nt}$ to $701 \mathrm{nt}$.).

\section{5'GAG AAA CCC GCT CAC CAG TCC TTT CTG AAT TGT CTG AAC TAT CAC CTG}

\section{CTG ACC ATC TGC T 31}

2). Construction of the template for the competitor:
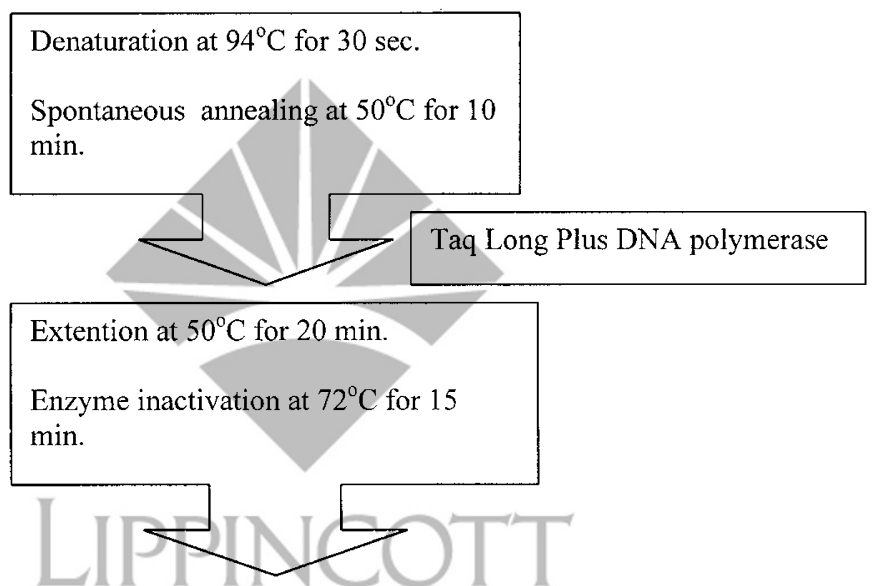

3). Purification and calibration of the competitor:

Figure 6.

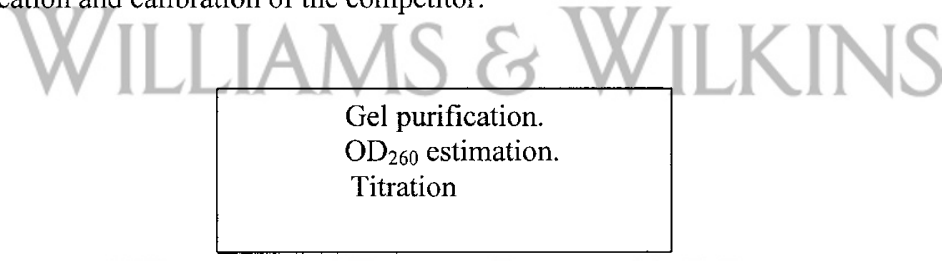

Generation of an internal cDNA standard (competitor) for qc RT-PCR. The downstream and upstream primers were designed to contain 18 complementary nucleotides at their $3^{\prime}$ ends (double-underlined sequences), which permitted their spontaneous annealing and allowed subsequent mutual priming extension of the annealed double-strand portion by DNA polymerase. After purification, the correct sequence of the extended product was verified. A primer pair (IPF)-17 and (IPR)-18 was used to amplify the Sp3 standard and the wild-type Sp3 fragment in the polymerase chain reactions. These primers are shown as bold sequences in the figure.

$3^{\prime}$ ends. This permits their spontaneous annealing. The competitive template was generated in a GeneAmp PCR system 9600 (Perkin-Elmer) using 2.5 pmol of each primer in Low Salt Taq Plus Long DNA polymerase buffer (Stratagene, La Jolla, California) by initial denaturation at $94^{\circ} \mathrm{C}$ for 30 seconds and cooling to $50^{\circ} \mathrm{C}$ for 10 minutes to allow spontaneous annealing. After a 10-minute incubation, $0.4 \mathrm{~mm}$ dNTPs and 0.5U Taq Plus Long polymerase were added to the reaction mix. The extension step was performed at $50^{\circ} \mathrm{C}$ for 20 minutes, followed by enzyme inactivation at $72^{\circ} \mathrm{C}$ for 15 minutes. The full-length extension product was verified by agarose gel electrophoresis and was purified from the gel using a QIAquick Gel Extraction Kit (50) (QIAGEN, Valencia, California). After purification, the yield was determined by gel electrophoresis using a Low DNA mass ladder (Life Technologies) as a standard and by measuring the optical density $\left(O D_{260}\right)$ of the purified competitor cDNA. After purification, the extended product sequence was verified by dideoxysequencing (Sanger et al, 1977) using Sequenase v.2.0 (Amersham, Piscataway, New Jersey).

\section{Titration Assay}

A titration assay was used to estimate the optimal quantity of standard cDNA for coamplification. A standard amount of the target cDNA, corresponding to $100 \mathrm{ng}$ of reverse-transcribed total RNA, and serial dilutions of the competitor were used. The PCR am- 
plification was performed in $20 \mathrm{ul}$ total volume of PCR mix containing $100 \mathrm{~mm}$ Tris- $\mathrm{HCl}(\mathrm{pH} 8.75), 100 \mathrm{~mm}$ $\mathrm{KCl}, 100 \mathrm{~mm}\left(\mathrm{NH}_{4}\right)_{2} \mathrm{SO}_{4}, 20 \mathrm{~mm} \mathrm{MgSO}{ }_{4}, 1 \%$ Triton $\mathrm{X}-100,1 \mathrm{mg} / \mathrm{ml}$ nuclease-free bovine serum albumin, $0.4 \mathrm{~mm}$ dNTPs, and $2.5 \mu \mathrm{M}$ of each Sp3 primer (IPF17 and IPR18). Five units of TaqPlus Long DNA polymerase (Stratagene) were added. Amplification was conducted for 30 cycles under the following conditions: the initial denaturation step was 1 minute at $94^{\circ} \mathrm{C}$, then 30 seconds at $94^{\circ} \mathrm{C}$, and then by a 30-second annealing step at $58^{\circ} \mathrm{C}$, and 30 -second elongation step at $72^{\circ} \mathrm{C}$. A final elongation step was performed for 1 minute at $72^{\circ} \mathrm{C}$. Thermal cycling was carried out with a GeneAmp PCR system 9600 (Perkin-Elmer). The amplified products were resolved on a $1.5 \%$ agarose gel and the DNA was visualized by ethidium bromide using a ultraviolet transilluminator.

A curve was generated using a standard amount of wild-type cDNA (100 ng) and increasing amounts of the DNA competitor. The resulting plot of amount of competitor versus the ratio of amplified target (At) to amplified standard (As), was used to identify the linear range for the amount of the competitor before reaching the plateau phase. The competitor fragment (At) signal decreased and disappeared when the initial amount of the competitor was lowered to less than 0.6 pg. A quantity within the linear range (12 pg) was used in subsequent semi-quantitative PCR assays (see below).

\section{qc RT-PCR}

For RNA quantification by qc RT-PCR, five PCR reactions were performed with a constant amount of cell subtype target cDNA (approximately the amount reverse transcribed from $100 \mathrm{ng}$ total RNA) and five different amounts of the cDNA competitor in serial dilutions $(1: 2,1: 4,1: 8,1: 16,1: 32)$, with the starting quantity being $50 \mathrm{pg}$. The amplification was carried out under the same PCR and cycling conditions that were described in the titration assay using TaqPlus Long DNA polymerase mix.

The two PCR products, wild-type (464 bp), and competitor (126 bp), were distinguished by size differences after agarose gel electrophoresis. Onedimensional gel analysis was performed to measure the optical density of the bands. The Polaroid photographs were scanned using a densitometry system with pdi Discovery Series Software. The optical densities of the bands were measured from the resultant graphic image and curves were generated (quantity of cDNA competitor versus optical density). The amount of Sp3 cDNA in each sample was determined from the dilution at which quantities of the competitor and target PCR products were equal. Controls that were run in each of the assays included a positive control (consisting of a known Sp3-positive cDNA), a negative (reagent) control (in which the cDNA was replaced with water), and a control for DNA contamination with isolated total RNA as a template.

\section{sq RT-PCR}

This procedure is a modification of qc RT-PCR that was used when the amount of mRNA was too small to carry out separate PCR reactions with each quantity of competitor (Siebert and Larrick, 1992). PCR reactions were performed with $12 \mathrm{pg}$ of the standard (competitor) DNA and an unknown amount of the target cDNA. The conditions of the PCR amplification were identical to those described above. Densitometry scanning of the gel, comparing the density of the target band with the density of the standard (competitor) band, was used to quantitate the amount of target cDNA.

\section{Acknowledgement}

The authors thank Dr. Karen Cresswell for flow cytometry support. The Flow Cytometry core facility was supported by National Cancer Institute grant P30CA51008.

\section{References}

Auboeuf D and Vidal H (1997). The use of the reverse transcription-competitive polymerase chain reaction to investigate the in vivo regulation of gene expression in small tissue samples. Anal Biochem 245:141-148.

Busin SA (2000). Absolute quantification of mRNA using real-time reverse transcription polymerase chain reaction assays. J Mol Endocrinol 25:169-193.

Foss DL, Baarsch MJ, and Murtaugh MP (1998). Regulation of hypoxanthine phosphoribosyltransferase, glyceraldehyde3-phosphate dehydrogenase and beta-actin mRNA expression in porcine immune cells and tissues. Anim Biotechnol 9:67-78.

Grekova M, Robinson E, Faerber M, Katz P, McFarland H, and Richert $J$ (1996). Deficient expression in multiple sclerosis of the inhibitory transcription factor Sp3 in mononuclear blood cells. Ann Neurol 40:108-112.

Grekova M, Scherer S, Trabb J, and Richert J (2000). Localization of the human SP3 gene to chromosome 7p14p15.2. The lack of expression in multiple sclerosis does not reflect abnormal gene organization. J Neuroimmunol 106: $214-219$

Hagen G, Muller S, Beato M, and Suske G (1992). Cloning by recognition site screening of two novel GT box binding proteins: A family of Sp1-related genes. Nucleic Acids Res 20:5519-5525.

Ke LD, Chen Z, and Yung WK (2000). A reliability test of standard-based quantitative PCR: Exogenous vs endogenous standards. Mol Cell Probes 14:127-135.

Kingsley C and Winoto A (1992). Cloning of GT box-binding proteins: A novel Sp1 multigene family regulating T-cell receptor gene expression. Mol Cell Biol 12:4251-4261.

Pang H, Miranda K, and Fine K (1998). Sp3 regulates fas expression in lung epithelial cells. Biochem J 333:209-213.

Raftery K, Sharefkin J, Limanni A, and Solomon R (1993). Construction of overlapping oligonucleotide template for the production of cRNA standards for quantitative reverse transcription polymerase chain reaction. Diagn Mol Pathol 2:120-124. 
Riedy MC, Timm EA Jr, and Stewart CC (1995). Quantitative RT-PCR for measuring gene expression. Biotechniques 18: 70-76.

Sanger F, Nicklen S, and Coulson AR (1977). DNA sequencing with chain-terminating inhibitors. Proc Natl Acad Sci USA 74:5463-5467.

Siebert PD and Larrick JW (1992). Competitive PCR. Nature 359:557-558.

Suske $\mathrm{G}$ (1999). The Sp-family of transcription factors. Gene 238:291-300.

Tone $\mathrm{M}$, Powell $\mathrm{M}$, Tone $\mathrm{Y}$, Thomas $\mathrm{S}$, and Waldmann $\mathrm{H}$ (2000). IL-10 gene expression Is controlled by the transcription factors Sp1 and Sp3. J Immunol 165:286-291.
Udvadia AJ, Templeton DJ, and Horowitz JM (1995). Functional interactions between the retinoblastoma $(\mathrm{Rb})$ protein and $\mathrm{Sp}$-family members: Superactivation by $\mathrm{Rb}$ requires amino acids necessary for growth suppression. Proc Natl Acad Sci USA 92:3953-3957.

Zimmermann K and Mannhalter JW (1996). Technical aspects of quantitative competitive PCR. Biotechniques 21: 268-279.

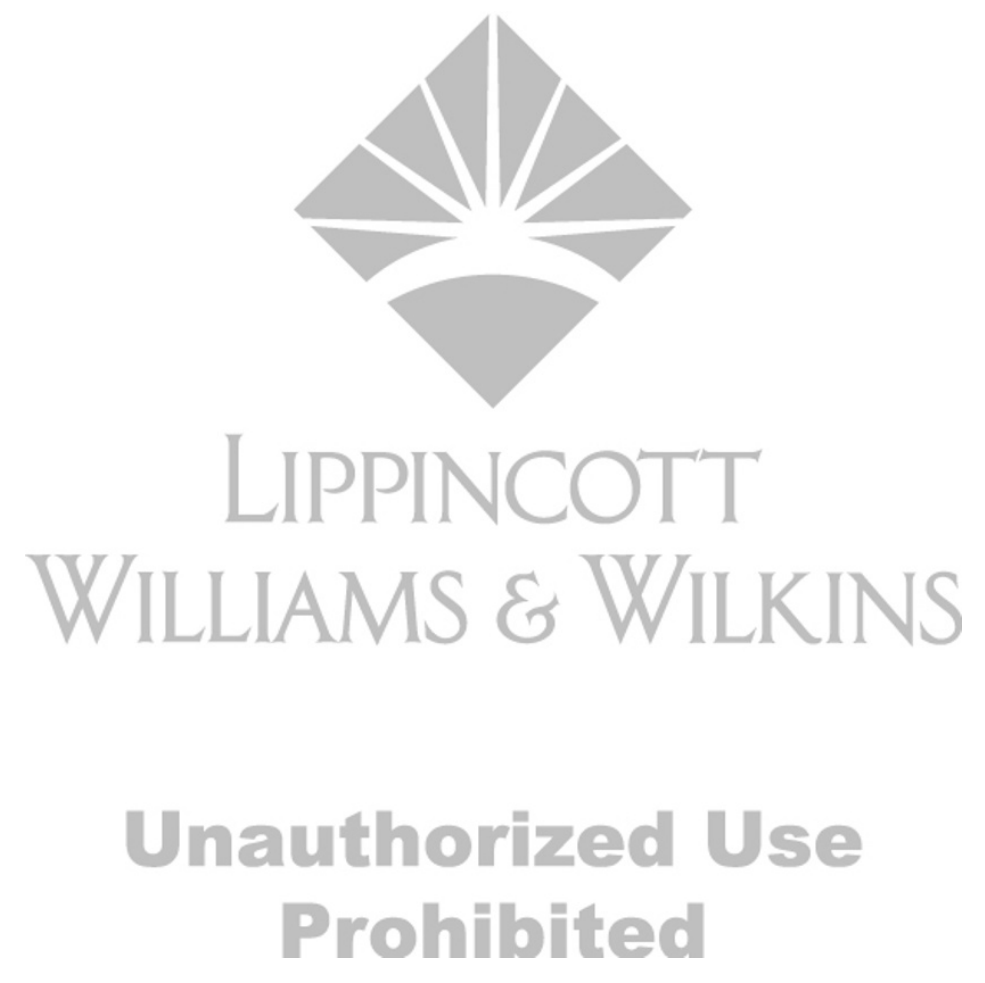

